\title{
Perancangan Sistem Pengukuran Kinerja Program Studi Akademi Angkatan Udara Sebagai Kesiapan Menghadapi Era Society 5.0
}

\author{
(Performance Measurement System Design \\ Air Force Academy Study Program as Preparedness for the Era \\ of Society 5.0)
}

\author{
Sah Feroza1, Gagat Riano ${ }^{2 *}$, Ismoyo ${ }^{3}$ \\ 1,2,3 Departemen Teknik Manajemen Industri, Akademi Angkatan Udara \\ E-mail:sahferoza@gmail.com,gagat.riano@aau.ac.id,bambang.imy@aau.ac.id
}

\begin{abstract}
In order for the implementation of the development of the basic potential of the academic ability of the air dimension at AAU to be carried out efficiently, harmoniously and efficiently, a performance measurement system (SPK) design that is integrated with quality assurance is required. By using the IPMS method for the design and the AHP method for its weighting, this study aims to develop a performance measurement system (SPK) in the Department of AAU. From this research, 13 requirements, 25 objectives and 44 key performance indicators (KPI) can be identified which are grouped into 10 Education components of TNI AU. The weighting results show that the criteria for students, namely cadets themselves, are the largest weights with a value of $21.75 \%$ and the lowest weight in the instruction package is 3.03\%. While the biggest weight for KPI is KPI NO 32, namely student achievement in international-scale competitions with a value of 0.4369.
\end{abstract}

Keywords - Performance Measurement System, IPMS Method, AHP Method, Department of Indonesian Airforce Academy.

Abstrak-Agar penyelenggaraan pembinaan kemampuan akademik potensi dasar matra udara di AAU dapat dilaksanakan secara efisien, serasi dan berdaya guna, diperlukan suatu rancangan sistem pengukuran kinerja (SPK) yang terintegrasi dengan jaminan mutu. Dengan menggunakan metode IPMS untuk perancangan dan metode AHP untuk pembobotannya, penelitian ini bertujuan untuk menyusun sistem pengukuran kinerja (SPK) di Departemen/ prodi AAU. Dari penelitian ini dapat diidentifikasi 13 requirement, 25 objectives dan 44 key performance indicator (KPI) yang dikelompokkan dalam 10 komponen Pendidikan TNI AU. Hasil pembobotan didapatkan bahwa kriteria Peserta didik yaitu Taruna sendiri merupakan bobot terbesar dengan nilai $21,75 \%$ dan bobot terendah pada Paket intruksi yaitu 3,03\%. Sedangkan bobot terbesar KPI adalah KPI NO 32, yaitu Prestasi peserta didik dalam kompetisi yang berskala Internasional dengan nilai 0,4369

Kata Kunci-Sistem Pengukuran Kinerja, Metode IPMS, Metode AHP, Departemen Elektronika AAU

\section{Pendahuluan}

Derkembangan ilmu pengetahuan dan teknologi yang sangat pesat, mendorong manusia mengembangkan suatu konsep untuk memanfaatkan hal tersebut agar kehidupannya menjadi lebih nyaman, dimana saat ini yang terbaru adalah konsep society 5.0 [1]. Konsep yang awalnya

\footnotetext{
* Penulis Korespondensi (Gagat Riano)
}

E-mail: gagat.riano@aau.ac.id 
diperkenalkan oleh Jepang pada tahun 2019 muncul untuk menjawab segala permasalahan yang timbul akibat revolusi 4.0 yang dinilai berpotensi mendegradasi peran manusia. Konsep society 5.0 mengintegrasikan dunia virtual dengan realita dan memungkinkan manusia untuk dapat menyelesaikan berbagai permasalahan sosial dengan dukungan teknologi [2]. Teknologi kecerdasan buatan (artificial intelligence) akan mentransformasi big data yang dikumpulkan melalui internet pada segala bidang kehidupan (the Internet of Things) menjadi suatu konsep kehidupan baru, yang akan membantu manusia menjalani kehidupan yang lebih baik [3] .

Untuk menghadapi hal tersebut, peran dunia pendidikan sangat strategis, terutama untuk meningkatkan kualtas sumber daya manusia (SDM). Di era society 5.0 manusia dituntut untuk memiliki kemampuan berpikir Higher Order Thinking Skills (HOTS), agar dapat meminimalisir kesenjangan pola pikir dan orientasi teknologi individu, sehingga terbentuk manusia dapat berintegrasi sepenuhnya dengan teknologi tanpa menimbulkan gejola dirupsi [3] . Manusia dituntut untuk lebih cepat menghasilkan solusi dalam memenuhi kebutuhannya. Keadaan ini mendorong manusia untuk terus mengali informasi, serta menciptakan inovasi baru guna menunjang kelangsungan hidupnya.

Akademi Angkatan Udara (AAU) mempunyai peran penting untuk menyiapkan SDM prajurit TNI Angkatan Udara setingkat perwira pertama [4]. Para perwira ini nantinya diharapkan mampu mengemban tugas sebagai prajurit TNI AU serta terus dapat mengembangkan kemampuannya sejalan dengan perkembangan teknologi di era society 5.0. Hal ini telah tersirat dalam sasaran pendidikan yang ditujukan untuk membentuk Taruna yang memiliki sifat Tri Sakti Viratama, yaitu sikap dan perilaku yang dapat diandalkan (tanggon), dapat beradaptasi dengan perkembangan ilmu pengetahuan dan teknologi (Tanggap) serta tangkas dan terampil di bidang latihan jasmani dan kemiliteran (Trengginas) [5]. Untuk itu AAU harus dapat menyiapkan seluruh aspek-aspek pendidikan yang ada di lembaga yang dikenal dengan 10 komponen pendidikan. Sebagai salah satu perguruan tinggi yang berada di bawah Direktorat Jendral Pendidikan Tinggi, AAU mempunyai kewajiban menjalani proses akreditasi yang dilakukan oleh Badan Akreditasi Nasional Perguruan Tingggi (BAN-PT), sebagai wujud pengukuran kinerja pelaksanaan organisasi secara menyeluruh [6]. Namun, yang menjadi permasalahan adalah pengukuran kinerja menurut standar akreditasi yang diterapkan oleh BAN PT lebih cenderung bersifat administratif, dimana pengukuran lebih banyak ditekankan kepada kelengkapan data yang terdokumentasi di dalam laporan administrasi harian yang ada pada sebuah Perguruan Tinggi. Padahal semestinya pengukuran kinerja perlu dikorelasikan dengan rencana strategis jangka panjang meliputi visi, misi dan rencana strategis sebuah Perguruan Tinggi [7].

Pengukuran kinerja terhadap semua komponen pendidikan saat ini dilakukan dengan melibatkan berbagai pihak seperti Direktorat Pengkajian (Dirjian), Kepala Penjaminan Mutu (Ka PM) dan seluruh Kepala Departemen/Prodi. Saat ini pengukuran kinerja tersebut dilakukan dengan mekanisme laporan evaluasi kerja dan laporan dan belum bersifat komprehensif terhadap proses-proses akademik, sehingga dipandang perlu untuk menyusun suatu sistem pengukuran kinerja yang dapat memberikan gambaran secara komprehensif pencapaian kinerja Departemen/prodi.

\section{LANDASAN TEORI}

Integrated Performance Measurement System (IPMS) merupakan salah satu metode yang sering digunakan dalam merancang sistem pengukuran kinerja (SPK) dengan bentuk terintegrasi, efektif dan efisien, berbasis kepada stakeholder (stakeholder requirement) [7]. Metode yang 
dibuat di Centrefor Strategic Manufacturing, University of Strathclyde, Glasgow ini terdiri dari beberapa langkah sebagai berikut:

1. Metode IPMS sebagai sistem kontrol kinerja, membagi organisasi dalam empat level, yaitu level bisnis, unit bisnis, proses bisnis dan aktivitas-aktivitas [8]. Pada tahap ini dilakukan identifikasi dan penetapan level dari elemen organisasi. Berdasarkan pembagian level organisasi dapat ditentukan ruang lingkup dari perancangan sistem pengukuran kinerja yaitu pada level unit bisnis sampai dengan level aktivitas.

2. Stakeholder Requirement Pada tiap-tiap level bisnis (organisasi) harus diketahui siapa saja stakeholder-nya atau pihak-pihak yang berkepentingan pada bisnis tersebut. Selanjutnya diidentifikasikan permintaan/ keinginan (requirement) mereka terhadap bisnis yang diistilahkan dengan Stakeholder Requirement. Stakeholder dapat meliputi; pemegang saham/pemilik, lingkungan sosial, pegawai/karyawan, pemerintah/instansi lain.

3. External Monitor. External monitor dilakukan untuk mengetahui posisi organisasi terhadap pesaing dan performansi/kinerja kelas dunia.

4. Objectives. Penyusunan tujuan (objectives) harus didasarkan pada keterlibatan dan prioritas perkembangan kebutuhan bersama dengan target dan skala waktu yang tepat. Dengan menggunakan cause effect tool seperti RONA, ROI trees dapat memberikan keterangan bahwa tujuan diperoleh melalui analisa yang akurat. Tujuan seharusnya juga didasarkan pada pemikiran sejumlah masukan, yaitu; permintaan stakeholder, praktek dan performansi bisnis kelas dunia, competitif gaps dan rencana pesaing, tingkat performansi dimana organisasi mampu mencapainya dengan berbagai batasan yang ada disebut target realistis, tingkat performansi dimana organisasi memiliki kemampuan untuk mencapainya dengan menghilangkan berbagai batasan yang ada yang dikatakan sebagai target potensial [9].

5.'Performance Measures. Suatu bisnis (organisasi) seharusnya memiliki pengukuran performansi yang benar-benar menunjukkan tingkat performansi yang dicapai, serta mampu menunjukkan seberapa berhasil pencapaian tujuan pada tiap level. Pengukuran performansi untuk setiap bisnis memiliki perbedaan, oleh sebab itu diperlukan kejelian dan pemahaman yang baik dari bisnis agar diperoleh pengukuran performansi yang benar. Untuk memperoleh ukuran performansi atau Key performance Indicator (KPI) yang benar perlu dilakukan validasi terhadap KPI yang dibuat. Kemudian apabila KPI tersebut sudah valid, maka KPI dispesifikasikan untuk memudahkan dalam proses pengukurannya. Proses spesifikasi KPI ini dilakukan untuk mengetahui deskripsi yang jelas tentang KPI, tujuan, keterkaitan dengan objectives, target dan ambang batas, formula/cara mengukur KPI, frekuensi pengukuran, frekuensi review, siapa yang mengukur, dan apa yang mereka kerjakan

\section{Metode Penelitian}

Langkah-langkah perancangan SPK dilakukan dengan tahapan sebagai berikut:

1. Pembagian Level Organisasi (stakeholder). Pembagian level organisasi AAU sesuai dengan kerangka kerja IPMS dan pendekatan sistem organisasi Departemen/prodi dapat dilihat pada gambar 1. 


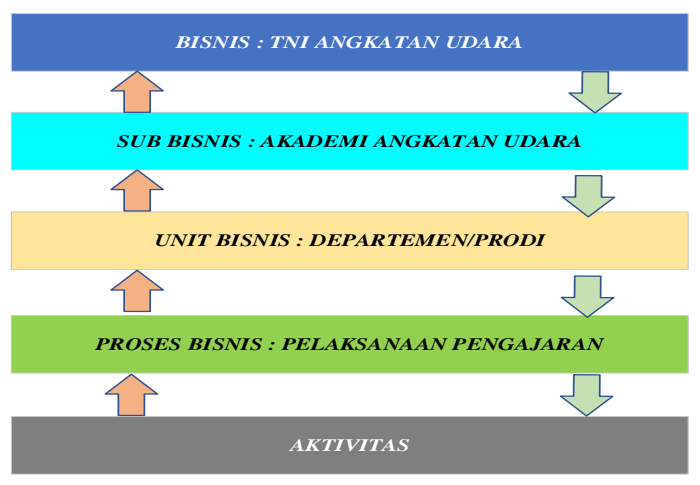

Gambar 1. Pembagian Level Organisasi AAU

a. Bisnis adalah TNI AU karena dalam melaksanakan tugasnya memerlukan pengawakan personel dengan sumber daya manusia (SDM) yang bertumpu pada kemampuan profesionalisme prajurit TNI $\mathrm{AU}[10]$

b. Sub Bisnis adalah AAU sebagai badan pelaksana pusat pada tingkat Mabesau yang bertugas menyelenggarakan pendidikan pertama perwira sukarela TNI AU tingkat akademik [4]

c. Unit Bisnis adalah Departemen/prodi yang merupakan bagian dari AAU, menyelenggarakan pengajaran/praktik/ pratikum materi sesuai departemen/prodi masingmasing [4]

2. Identifikasi Stakeholder Requirement. Identifikasi kebutuhan stakeholder dilakukan dengan mengirimkan kuisoner daftar requirement kepada expert yaitu Dirjian dan KPM AAU. Penentuan daftar requirement awal penelitian ini dikembangkan berdasarkan pengukuran kinerja menurut BAN-PT dan penelitian Suartika tentang perancangan sistem pengukuran kinerja di jurusan Teknik Mesin Universitas Mataram [7], yang telah banyak menjadi rujukan awal penelitian sejenis, tentunya dengan sedikit penyesuaian dengan kondisi di AAU. Dari 15 requirement awal diambil 13 requirement saja. Daftar requirement dapat dilihat pada tabel 1.

TABEL 1

STAKEHOLDER REQUIREMENT

\begin{tabular}{|c|l|}
\hline \hline NO & \multicolumn{1}{|c|}{ STAKEHOLDER REQUIREMENT } \\
\hline 1 & Pelaksanaan pendidikan di Departemen Berjalan Dengan baik \\
2 & Keuangan Departemen dikelola dengan baik dan bertanggung jawab \\
3 & Lulusan yang dihasilkan departemen relevan dengan kebutuhan satuan \\
4 & Terealisasinya program-program departemen \\
5 & Meningkatnya minat baca dan belajar Taruna \\
6 & Pelaksanaan perkuliahan sesuai dengan silabus, GBPP dan SAP \\
7 & Meningkatnya kualitas penelitian dosen dan Taruna \\
8 & Kesejahteraan dan reward SDM departemen diperhatikan \\
9 & Ketersediaan alins alongins pengajaran sebelum perkuliahan dimulai \\
10 & Lulus dengan indeks prestasi (IP) tinggi \\
11 & Tersedianya diktat/modul matakuliah dan pratikum \\
12 & Mendapatkan lulusan berkemampuan menggunakan bahasa Inggris \\
13 & Lulusan yang mampu memecahkan permasalahan sederhana di satuan kerja \\
\hline \hline
\end{tabular}


3. Eksternal monitoring. Eksternal monitoring dilakukan melalui riset in-house terhadap beberapa dokumen Pendidikan AAU, yang meliputi Rencana Operasi Pendidikan Akademi Angkatan Udara Tahun Pendidikan 2019/2020, Rencana Strategis Akademi Angkatan Udara Tahun 2020 Sampai Dengan 2024, Laporan Pendidikan Taruna Akademi Angkatan Udara Periode Tahun 2015-2019 dan Laporan Kajian Evaluasi Pelaksanaan Pendidikan

4. Penentuan Objectives dan KPI. Penentuan objectives dilakukan untuk memenuhi kebutuhan stakeholder, dimana agar dapat diukur tingkat keberhasilannya, objectives ini harus dilengkapi indikator keberhasilan dalam hal ini KPI. Pada penelitian ini daftar objectives dan KPI awal ditentukan dengan merujuk boring akreditasi BAN-PT dan penelitian Suartika [7]. Daftar ini kemudian di brainstrooming dengan KPM untuk memastikan kesesuaiannya. Daftar objectives dan KPI dapat dilihat pada tabel 2

TABEL 2

DAFTAR REQUIREMENT, OBJECTIVES DAN KEY PERFORMANCE INDICATOR

\begin{tabular}{|c|c|c|c|c|c|}
\hline \multirow{2}{*}{$\begin{array}{l}\text { REQUIREM } \\
\text { ENT }\end{array}$} & \multicolumn{2}{|c|}{ OBJECTIVES } & \multicolumn{2}{|c|}{$\begin{array}{l}\text { KEY PERFORMANCE } \\
\text { INDICATOR }\end{array}$} & \multirow[t]{2}{*}{ FORMULA KPI } \\
\hline & NO & URAIAN & NO & URAIAN & \\
\hline \multirow{5}{*}{$\begin{array}{l}\text { Pelaksanaan } \\
\text { pendidikan di } \\
\text { Dep berjalan } \\
\text { dengan baik. }\end{array}$} & \multirow{3}{*}{1} & \multirow{3}{*}{$\begin{array}{l}\text { Kualitas dosen dan } \\
\text { antap ditingkatkan }\end{array}$} & 1 & $\begin{array}{l}\text { Rasio dosen } \\
\text { berpendidikan } \\
\text { lanjut. }\end{array}$ & $\begin{array}{l}\{\text { Jumlah }(S 2+S 3) /(\text { Total } \\
\text { dosen })\} \times 100 \% .\end{array}$ \\
\hline & & & 2 & $\begin{array}{l}\text { Rasio dosen yang } \\
\text { telah pelatihan } \\
\text { metode } \\
\text { pengajaran }\end{array}$ & $\begin{array}{l}\text { \{Jumlah dosen yang telah } \\
\text { pelatihan/Total dosen }\} x \\
100 \% .\end{array}$ \\
\hline & & & 3 & $\begin{array}{l}\text { Rasio Pendidikan } \\
\text { untuk antap. }\end{array}$ & $\begin{array}{l}\text { \{Jumlah antap } \\
\text { ditraining/total karyawan }\} \\
x 100 \% .\end{array}$ \\
\hline & 2 & $\begin{array}{l}\text { Proses belajar } \\
\text { mengajar } \\
\text { kuantitasnya } \\
\text { ditingkatkan. } \\
\end{array}$ & 4 & $\begin{array}{l}\text { Rata-rata } \\
\text { prosentase } \\
\text { kehadiran dosen. }\end{array}$ & $\begin{array}{l}\{\text { Jumlah perkuliahan } / 18\} x \\
100 \%\end{array}$ \\
\hline & 3 & $\begin{array}{l}\text { Mata kuliah } \\
\text { dibuatkan Silabus, } \\
\text { SAP dan GBPP }\end{array}$ & 5 & $\begin{array}{l}\text { Prosentase mata } \\
\text { kuliah yang ada } \\
\text { Silabus, SAP dan } \\
\text { GBPPnya. }\end{array}$ & $\begin{array}{l}\{\text { Jumlah MK yang ada } \\
\text { Silabus, SAP dan } \\
\text { GBPP/Jumlah MK\} x } \\
100 \% \text {. }\end{array}$ \\
\hline \multirow{2}{*}{$\begin{array}{l}\text { Keuangan } \\
\text { Jurusan } \\
\text { dikelola } \\
\text { dengan baik } \\
\text { dan } \\
\text { bertanggung } \\
\text { jawab }\end{array}$} & 4 & $\begin{array}{l}\text { Departemen } \\
\text { membuat laporan } \\
\text { keuangan secara } \\
\text { rutin }\end{array}$ & 6 & $\begin{array}{l}\text { Prosentase } \\
\text { laporan keuangan } \\
\text { yang tepat waktu. }\end{array}$ & $\begin{array}{l}\text { \{Laporan keuangan yang } \\
\text { tepat waktu /total laporan } \\
\text { yang dibuat }\} \times 100 \% \text {. }\end{array}$ \\
\hline & 5 & $\begin{array}{l}\text { Departemen mampu } \\
\text { menggali dana } \\
\text { masyarakat. }\end{array}$ & 7 & $\begin{array}{l}\text { Rata-rata dana } \\
\text { masyarakat yang } \\
\text { dapat digali } \\
\text { perbulan. }\end{array}$ & $\begin{array}{l}\text { [Jumlah dana yang } \\
\text { masuk/Jumlah bulan]. } \\
\text { Perbulan. }\end{array}$ \\
\hline $\begin{array}{l}\text { Lulusan yang } \\
\text { dihasilkan } \\
\text { Dep relevan } \\
\text { dengan } \\
\text { kebutuhan } \\
\text { satuan kerja. } \\
\end{array}$ & 6 & $\begin{array}{l}\text { Merancang dan } \\
\text { mengembangkan } \\
\text { kurikulum sesuai } \\
\text { dengan kebutuhan } \\
\text { satker. }\end{array}$ & 8 & $\begin{array}{l}\text { Jumlah satker } \\
\text { yang diikutkan } \\
\text { dalam } \\
\text { perancangan dan } \\
\text { pengembangan } \\
\text { kurikulum. } \\
\end{array}$ & $\begin{array}{l}\text { Dijumlahkan industri yang } \\
\text { diikutkan dalam } \\
\text { perancangan dan } \\
\text { pengembangan kurikulum. }\end{array}$ \\
\hline \multirow{2}{*}{$\begin{array}{l}\text { Terealisasiny } \\
\text { a program- } \\
\text { program Dep }\end{array}$} & \multirow[b]{2}{*}{7} & \multirow{2}{*}{$\begin{array}{l}\text { Mengadakan } \\
\text { pertemuan (rutin } \\
\text { maupun insidential) } \\
\text { untuk sosialisasi } \\
\text { programprogram } \\
\text { Departemen. }\end{array}$} & 9 & $\begin{array}{l}\text { Prosentase } \\
\text { kehadiran peserta } \\
\text { pertemuan. }\end{array}$ & $\begin{array}{l}\text { \{[Jumlah peserta yang } \\
\text { hadir/ jumlah peserta yang } \\
\text { diundang] } x 100 \%\} \text {. }\end{array}$ \\
\hline & & & 10 & $\begin{array}{l}\text { Prosentase } \\
\text { program yang } \\
\text { terlaksana. }\end{array}$ & $\begin{array}{l}\text { [Jumlah program } \\
\text { terlaksana/Total program } \\
\text { yang direncanakan] } x \\
100 \%\end{array}$ \\
\hline \multirow{2}{*}{$\begin{array}{l}\text { Meningkatny } \\
\text { a minat baca } \\
\text { dan belajar } \\
\text { Taruna }\end{array}$} & \multirow[t]{2}{*}{8} & \multirow{2}{*}{$\begin{array}{l}\text { Departemen } \\
\text { membuatkan } \\
\text { fasilitas } \\
\text { perpustakaan }\end{array}$} & 11 & $\begin{array}{l}\text { Rasio kapasitas } \\
\text { perpustakaan } \\
\text { terhadap jumlah } \\
\text { mahasiswa } \\
\end{array}$ & $\begin{array}{l}\{[\text { Kapasitas } \\
\text { perpustakaan/Jumlah } \\
\text { mahasiswa] x } 100 \%\}\end{array}$ \\
\hline & & & 12 & $\begin{array}{l}\text { Rasio referensi } \\
\text { terhadap Taruna. }\end{array}$ & $\begin{array}{l}\{[\text { Jumlah buku/Jumlah } \\
\text { Taruna }] \times 100 \%\} .\end{array}$ \\
\hline
\end{tabular}


TABEL 2. (LANJUTAN)

\begin{tabular}{|c|c|c|c|c|c|}
\hline \multirow{2}{*}{$\begin{array}{l}\text { REQUIREM } \\
\text { ENT }\end{array}$} & \multicolumn{2}{|c|}{ OBJECTIVES } & \multicolumn{2}{|c|}{$\begin{array}{l}\text { KEY PERFORMANCE } \\
\text { INDICATOR } \\
\end{array}$} & \multirow{2}{*}{ FORMULA KPI } \\
\hline & NO & URAIAN & NO & URAIAN & \\
\hline & \multirow{2}{*}{9} & \multirow{2}{*}{$\begin{array}{l}\text { Dosen diwajibkan } \\
\text { memberikan } \\
\text { tugastugas MK yang } \\
\text { dapat memotivasi } \\
\text { Taruna untuk } \\
\text { mencari referensi di } \\
\text { Perpustakaan }\end{array}$} & 13 & $\begin{array}{l}\text { Jumlah } \\
\text { pengunjung } \\
\text { Perpustakaan } \\
\text { perhari. }\end{array}$ & $\begin{array}{l}\text { Dijumlahkan pengunjung } \\
\text { Perpustakaan perhari }\end{array}$ \\
\hline & & & 14 & $\begin{array}{l}\text { Rasio taruna yang } \\
\text { menggunakan } \\
\text { fasilitas } \\
\text { Perpustakaan. }\end{array}$ & $\begin{array}{l}\{[\text { Jumlah Taruna yang } \\
\text { menggunakan } \\
\text { Perpustakaan/ Total } \\
\text { Taruna TM }] \times 100 \%\} .\end{array}$ \\
\hline $\begin{array}{l}\text { Pelaksanaan } \\
\text { perkuliahan } \\
\text { sesuai dengan } \\
\text { silabus, } \\
\text { GBPP dan } \\
\text { SAP. }\end{array}$ & 10 & $\begin{array}{l}\text { Departemen } \\
\text { melakukan } \\
\text { monitoring } \\
\text { kesesuaian } \\
\text { perkuliahan terhadap } \\
\text { Silabus, SAP dan } \\
\text { GBPP. }\end{array}$ & 15 & $\begin{array}{l}\text { Prosentase } \\
\text { perkuliahan yang } \\
\text { sesuai dengan } \\
\text { Silabus, SAP dan } \\
\text { GBPP } \\
\text { persemester. }\end{array}$ & $\begin{array}{l}\{[\text { Jumlah perkuliahan yang } \\
\text { sesuai Silabus, SAP dan } \\
\text { GBPP/Total } \\
\text { perkuliahan }] \text { /persemester }\} \\
\text { x } 100 \%\end{array}$ \\
\hline \multirow{5}{*}{$\begin{array}{l}\text { Meningkatny } \\
\text { a kualitas } \\
\text { penelitian } \\
\text { dosen dan } \\
\text { Taruna }\end{array}$} & \multirow[t]{2}{*}{11} & \multirow{2}{*}{$\begin{array}{l}\text { Memberikan } \\
\text { pelatihan metodelogi } \\
\text { penelitian kepada } \\
\text { dosen. }\end{array}$} & 16 & $\begin{array}{l}\text { Rasio dosen yang } \\
\text { telah } \\
\text { mendapatkan } \\
\text { pelatihan } \\
\text { metodologi } \\
\text { penelitian. } \\
\end{array}$ & $\begin{array}{l}\text { [Jumlah dosen yang telah } \\
\text { pelatihan/Total dosen] x } \\
100 \%\end{array}$ \\
\hline & & & 17 & $\begin{array}{l}\text { Prosentase } \\
\text { penelitian dosen } \\
\text { yang } \\
\text { mendapatkan hak } \\
\text { paten (HAKI). }\end{array}$ & $\begin{array}{l}\{[\text { Jumlah penelitian yang } \\
\text { dapat HAKI/jumlah } \\
\text { penelitian yang diusulan }] \mathrm{x} \\
100 \%\} \text {. }\end{array}$ \\
\hline & \multirow[b]{2}{*}{12} & \multirow{2}{*}{$\begin{array}{l}\text { Departemen } \\
\text { memberikan dana } \\
\text { kepada dosen yang } \\
\text { hasil penelitiannya } \\
\text { dipresentasikan } \\
\text { dalam seminar } \\
\text { nasional maupun } \\
\text { internasional. }\end{array}$} & 18 & & $\begin{array}{l}\text { [Jumlah penelitian dosen } \\
\text { yang mandapatkan } \\
\text { dana/Total penelitian } \\
\text { dosen] x } 100 \% \text {. }\end{array}$ \\
\hline & & & 19 & $\begin{array}{l}\text { Rasio penelitian } \\
\text { dosen yang } \\
\text { diterbitkan dalam } \\
\text { jurnal } \\
\text { terakreditasi. }\end{array}$ & $\begin{array}{l}\{[\text { Jumlah penelitian dosen } \\
\text { yang diterbitkan dalam } \\
\text { jurnal terakreditasi/Total } \\
\text { penelitian dosen }] \text { x } 100 \%\} \text {. }\end{array}$ \\
\hline & 13 & $\begin{array}{l}\text { Melibatkan Taruna } \\
\text { dalam penelitian } \\
\text { dosen. }\end{array}$ & 20 & $\begin{array}{l}\text { Prosentase Taruna } \\
\text { yang terlibat } \\
\text { dalam penelitian } \\
\text { dosen. }\end{array}$ & $\begin{array}{l}\text { [Jumlah Taruna yang } \\
\text { terlibat/Total Taruna] x } \\
100 \% .\end{array}$ \\
\hline $\begin{array}{l}\text { Kesejahteraan } \\
\text { dan reward } \\
\text { SDM } \\
\text { Departemen } \\
\text { diperhatikan. }\end{array}$ & 14 & $\begin{array}{l}\text { Melakukan } \\
\text { koordinasi dengan } \\
\text { Dirdik sehingga } \\
\text { pembayaran gaji dan } \\
\text { honor-honor tepat } \\
\text { waktu. }\end{array}$ & 21 & $\begin{array}{l}\text { Prosentase } \\
\text { pembayaran gaji } \\
\text { dan honor-honor } \\
\text { yang tepat waktu. }\end{array}$ & $\begin{array}{l}\text { [Jumlah gaji dan honor } \\
\text { yang dibayar tepat } \\
\text { waktu/Total gaji dan honor } \\
\text { yang harus dibayarkan] x } \\
100 \% \text {. }\end{array}$ \\
\hline \multirow{2}{*}{$\begin{array}{l}\text { Ketersediaan } \\
\text { alat bantu } \\
\text { proses belajar } \\
\text { mengajar } \\
\text { sebelum } \\
\text { perkuliahan } \\
\text { dimulai. }\end{array}$} & 15 & $\begin{array}{l}\text { Memberikan SK } \\
\text { untuk kegiatan- } \\
\text { kegiatan yang } \\
\text { melibatkan SDM } \\
\text { departemen yang } \\
\text { tepat waktu. }\end{array}$ & 22 & $\begin{array}{l}\text { Prosentase SK } \\
\text { yang tepat waktu. }\end{array}$ & $\begin{array}{l}\text { [Jumlah SK yang tepat } \\
\text { waktu/Jumlah SK yang } \\
\text { diterbitkan] x } 100 \% \text {. }\end{array}$ \\
\hline & 16 & $\begin{array}{l}\text { Melibatkan antap } \\
\text { dalam panitia } \\
\text { pelaksanaan ujian } \\
\text { (UAS dan UTS). }\end{array}$ & 23 & $\begin{array}{l}\text { Rasio antap yang } \\
\text { terlibat dalam } \\
\text { panitia ujian. }\end{array}$ & $\begin{array}{l}\text { [Jumlah antap yang } \\
\text { terlibat/Total karyawan] x } \\
100 \% \text {. }\end{array}$ \\
\hline
\end{tabular}

TABEL 2. (LANJUTAN) 


\begin{tabular}{|c|c|c|c|c|c|}
\hline \multirow[t]{2}{*}{$\begin{array}{l}\text { REQUIREM } \\
\text { ENT }\end{array}$} & \multicolumn{2}{|c|}{ OBJECTIVES } & \multicolumn{2}{|c|}{$\begin{array}{c}\text { KEY PERFORMANCE } \\
\text { INDICATOR }\end{array}$} & \multirow[t]{2}{*}{ FORMULA KPI } \\
\hline & NO & URAIAN & NO & URAIAN & \\
\hline & 17 & $\begin{array}{l}\text { Menyediakan alat } \\
\text { bantu proses belajar } \\
\text { mengajar untuk } \\
\text { setiap ruang kuliah. }\end{array}$ & 24 & $\begin{array}{l}\text { Rasio alat bantu } \\
\text { belajar mengajar } \\
\text { dengan ruang } \\
\text { kuliah. }\end{array}$ & $\begin{array}{l}\{[\text { Jumlah alat bantu/Jumlah } \\
\text { ruang kuliah }] \times 100 \%\} \text {. }\end{array}$ \\
\hline \multirow{4}{*}{$\begin{array}{l}\text { Nilai indek } \\
\text { prestasi (IP) } \\
\text { tinggi dan } \\
\text { mampu } \\
\text { bekerja }\end{array}$} & \multirow{2}{*}{18} & \multirow{2}{*}{$\begin{array}{l}\text { Memotivasi Taruna } \\
\text { agar mencapai IPK } \\
\text { yang tinggi }\end{array}$} & 25 & $\begin{array}{l}\text { Lama studi rata- } \\
\text { rata lulusan }\end{array}$ & $\begin{array}{l}\text { [ Jumlah lama studi } \\
\text { lulusan/jumlah lulusan] }\end{array}$ \\
\hline & & & 26 & $\begin{array}{l}\text { IPK rata-rata } \\
\text { lulusan. }\end{array}$ & $\begin{array}{l}\text { [Jumlah IPK } \\
\text { lulusan/jumlah lulusan]. }\end{array}$ \\
\hline & 19 & $\begin{array}{l}\text { Pembuatan jadwal } \\
\text { konsultasi TA } \\
\text { Tambahan }\end{array}$ & 27 & $\begin{array}{l}\text { Lama waktu rata- } \\
\text { rata penyelesaian } \\
\text { TA }\end{array}$ & $\begin{array}{l}\text { [Jumlah lama waktu } \\
\text { penyelesaian TA/jumlah } \\
\text { mahasiswa TA] }\end{array}$ \\
\hline & 20 & $\begin{array}{l}\text { TA yang sesuai } \\
\text { dengan } \\
\text { permasalahan di } \\
\text { Satker }\end{array}$ & 28 & $\begin{array}{l}\text { Jumlah TA yang } \\
\text { relevan. }\end{array}$ & $\begin{array}{l}\text { [Jumlah TA yang } \\
\text { relevan/jumlah TA secara } \\
\text { total }\end{array}$ \\
\hline \multirow{2}{*}{$\begin{array}{c}\text { Tersedianya } \\
\text { modul/diktat } \\
\text { mata kuliah } \\
\text { dan petunjuk } \\
\text { praktikum. }\end{array}$} & \multirow[b]{2}{*}{21} & \multirow{2}{*}{$\begin{array}{l}\text { Pembuatan diktat } \\
\text { dan modul praktek } \\
\text { yang sesuai dengan } \\
\text { perkembangan iptek. }\end{array}$} & 29 & $\begin{array}{l}\text { Rasio diktat } \\
\text { dengan matkul } \\
\text { yang dibuat } \\
\end{array}$ & $\begin{array}{l}\text { [Jumlah diktat yang } \\
\text { dibuat/jumlah MK ] x } \\
100 \%\end{array}$ \\
\hline & & & 30 & $\begin{array}{l}\text { Rasio buku } \\
\text { petunjuk } \\
\text { praktikum. }\end{array}$ & $\begin{array}{l}\text { [Jumlah modul } \\
\text { praktikum/Total praktikum } \\
\text { yang diselenggarakan] x } \\
100 \%\end{array}$ \\
\hline \multirow{2}{*}{$\begin{array}{c}\text { Mendapatkan } \\
\text { lulusan yang } \\
\text { mampu } \\
\text { bekerja dan } \\
\text { berkomunikas } \\
\text { i dalam } \\
\text { bahasa } \\
\text { Inggris. }\end{array}$} & 22 & $\begin{array}{l}\text { Menambah lulusan } \\
\text { tentang pengetahuan } \\
\text { praktis dengan } \\
\text { mengadakan } \\
\text { pelatihan } \\
\text { bersertifikat. }\end{array}$ & 31 & $\begin{array}{l}\text { Rasio lulusan } \\
\text { yang bersertifikat } \\
\text { pengetahuan } \\
\text { praktis. }\end{array}$ & $\begin{array}{l}\text { [Jumlah lulusan yang } \\
\text { bersertifikat/Jumlah } \\
\text { lulusan] x } 100 \% \text {. }\end{array}$ \\
\hline & 23 & $\begin{array}{l}\text { Membentuk english } \\
\text { class dan } \\
\text { mensyaratkan } \\
\text { bahasa Inggris pada } \\
\text { hari dan tempat- } \\
\text { tempat tertentu } \\
\text { untuk meningkatkan } \\
\text { kemampuan bahasa } \\
\text { inggris lulusan. }\end{array}$ & 32 & $\begin{array}{l}\text { Prosentase Nilai } \\
\text { TOEFL lulusan } \geq \\
400\end{array}$ & $\begin{array}{l}\text { [Jumlah lulusan nilai } \\
\text { TOEFL } \geq 400 / \text { Jumlah } \\
\text { lulusan] x } 100 \% \text {. }\end{array}$ \\
\hline \multirow{3}{*}{$\begin{array}{l}\text { Lulusan yang } \\
\text { mampu } \\
\text { memecahkan } \\
\text { permasalahan } \\
\text { sederhana } \\
\text { disatuan kerja }\end{array}$} & \multirow[b]{2}{*}{24} & \multirow{2}{*}{$\begin{array}{l}\text { Melibatkan Taruna } \\
\text { dalam kegiatan } \\
\text { pengabdian kepada } \\
\text { masyarakat (dalam } \\
\text { bentuk latsitarda dan } \\
\text { bentuk lainnya }\end{array}$} & 33 & $\begin{array}{l}\text { Jumlah } \\
\text { pengabdian } \\
\text { kepada } \\
\text { masyarakat } \\
\end{array}$ & $\begin{array}{l}\text { Dijumlahkan penelitian } \\
\text { dan pengabdian pada } \\
\text { masyarakat. }\end{array}$ \\
\hline & & & 34 & $\begin{array}{l}\text { Prosentase Taruna } \\
\text { yang terlibat } \\
\text { dalam pengabdian } \\
\text { kepada } \\
\text { masyarakat dosen. }\end{array}$ & $\begin{array}{l}\text { [Jumlah Taruna yang } \\
\text { dilibatkan/Jumlah } \\
\text { pengabdian masyarakat } \\
\text { dosen] x } 100 \% \text {. }\end{array}$ \\
\hline & 25 & $\begin{array}{l}\text { Pelaksanaan Praktek } \\
\text { lapangan di Satker }\end{array}$ & 35 & $\begin{array}{l}\text { Jumlah kegiatan } \\
\text { praktek di satker }\end{array}$ & $\begin{array}{l}\text { Dijumlahkan kegiatan } \\
\text { yang ada. }\end{array}$ \\
\hline
\end{tabular}

5. Validasi KPI. Setelah KPI teridentifikasi, maka KPI disusun dalam bentuk hierarki SPK dengan ketentuan di level tertinggi kinerja Departemen/prodi, level kedua kriteria dalam hal ini 10 komponen Pendidikan dan level terbawah adalah KPI, seperti terlihat pada gambar 2. Proses validasi dilakukan melalui diskusi dan brainstorming pengambil keputusan, dalam hal ini seluruh Kadep/kaprodi, untuk memberikan pengukuran apakah hierarki SPK yang disusun sudah sesuai atau valid dengan pendekatan sistem organisaasi yang diinginkan. Berdasarkan proses validasi yang dilakukan ternyata KPI yang tersusun dinyatakan valid berdasarkan pendekatan sistem organisasi Departemen/prodi. 


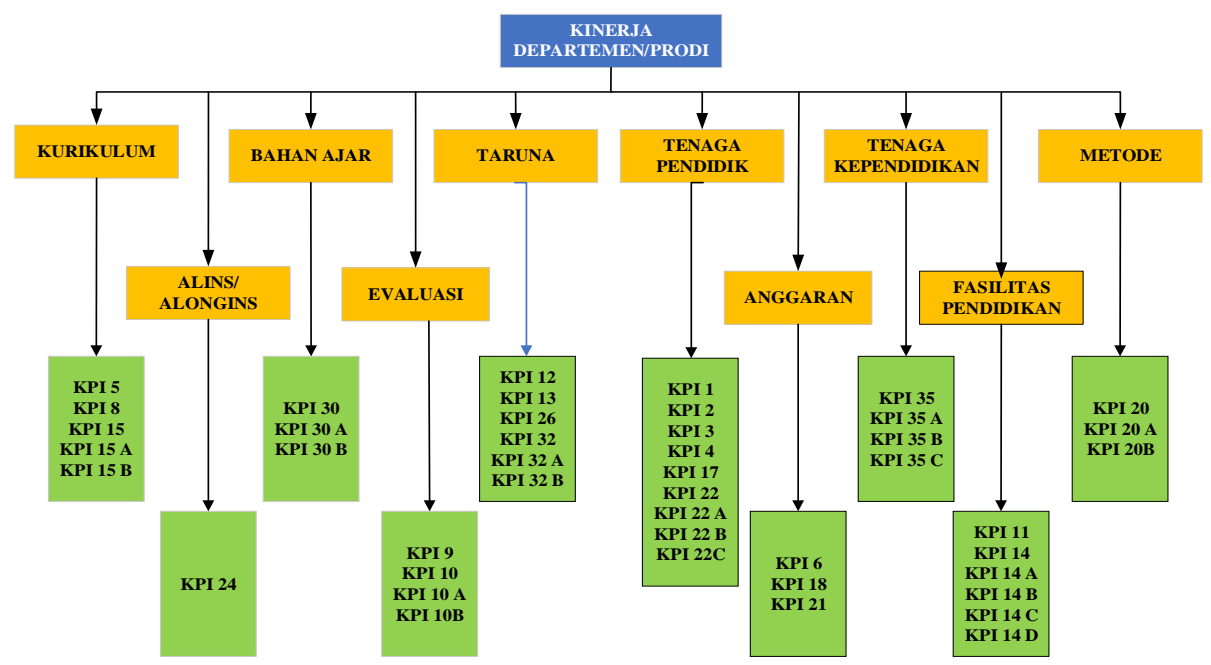

Gambar 2. Hierarki Kinerja Program Studi AAU

6. Spesifikasi KPI. Tahap ini dilakukan untuk mendiskripsikan KPI secara detail, meliputi tujuan, keterkaitan dengan objectives, target dan ambang batas, formula atau cara ukur, frekuensi pengukuran, pihak yang mengukur dan bagaimana cara pengukuran sebagai indikator pengukuran bagi auditor.

7. Pembobotan KPI. Kriteria dan KPI yang telah divalidasi diajukan kembali kepada expert dalam hal ini Dirjian, Ka PM, Koordinator Dosen (Koordos), Kadep Aeronautika (AE), Kadep Elektronika (LEK) dan Kadep Teknik Manajemen Industri (TMI) untuk dilakukan pembobotan. Pembobotan dilakukan dengan pendekatan Analitycal Hierarchy Process (AHP), yaitu pengukuran berupa perbandingan berpasangan/pairwise [11]. Hasil pembobotan dapat dilihat pada tabel 3

TABEL 3

PEMBOBOTAN KRITERIA DAN KPI DEPARTEMEN/PRODI AAU

\begin{tabular}{|c|c|c|c|c|}
\hline NO & KOMPONEN & $\begin{array}{c}\text { BOBOT } \\
\text { KOMPONEN }\end{array}$ & KPI & BOBOT KPI \\
\hline \multirow{6}{*}{1} & \multirow{6}{*}{ TARUNA } & \multirow{6}{*}{0,2175} & 12. Rasio referensi terhadap Taruna. & 0,0788 \\
\hline & & & 13. Jumlah pengunjung Perpustakaan Perhari. & 0,0704 \\
\hline & & & 26. IPK rata-rata lulusan. & 0,1037 \\
\hline & & & 32. Prosentase nilai ALCPT. & 0,0931 \\
\hline & & & $\begin{array}{l}\text { 32a. Prestasi peserta didik dalam kompetisi yang } \\
\text { berskala Nasional. }\end{array}$ & 0,2171 \\
\hline & & & $\begin{array}{l}\text { 32b. Prestasi peserta didik dalam kompetisi yang } \\
\text { berskala Internasional. }\end{array}$ & 0,4369 \\
\hline \multirow{4}{*}{2} & \multirow{4}{*}{$\begin{array}{l}\text { TENAGA } \\
\text { KEPENDIDIKAN }\end{array}$} & \multirow{4}{*}{0,1964} & 35. Jumlah kegiatan praktek di satker. & 0,056 \\
\hline & & & $\begin{array}{l}\text { 35a. Sertifikat/kualifikasi yang mendukung sebagai } \\
\text { laboran. }\end{array}$ & 0,5218 \\
\hline & & & 35b. Jumlah publikasi Laboran. & 0,1836 \\
\hline & & & $\begin{array}{l}\text { 35c. Kualitas pelayanan tenaga Pendidikan terhadap } \\
\text { Taruna }\end{array}$ & 0,2386 \\
\hline \multirow{4}{*}{3} & \multirow{4}{*}{$\begin{array}{l}\text { TENAGA } \\
\text { PENDIDIK }\end{array}$} & \multirow{4}{*}{0,1841} & 1. Rasio Dosen berpendidikan Lanjut. & 0,2557 \\
\hline & & & 2. Rasio Dosen yang telah pelatihan metode pengajaran. & 0,0735 \\
\hline & & & 3. Rasio Pendidikan Untuk antap. & 0,0366 \\
\hline & & & 4. Rata-rata Prosentase Kehadiran dosen. & 0,0488 \\
\hline
\end{tabular}


TABEL 3. (LANJUTAN)

\begin{tabular}{|c|c|c|c|c|}
\hline NO & KOMPONEN & $\begin{array}{c}\text { BOBOT } \\
\text { KOMPONEN }\end{array}$ & KPI & $\begin{array}{l}\text { BOBOT } \\
\text { KPI }\end{array}$ \\
\hline & & & $\begin{array}{l}\text { 17. Prosentase penelitian dosen yang } \\
\text { mendapatkan hak paten (HAKI). }\end{array}$ & 0,0938 \\
\hline & & & 22. Prosentase SK yang tepat waktu. & 0,0752 \\
\hline & & & 22a. jumlah SKS mengajar dosen. & 0,0794 \\
\hline & & & 22b. Skep jabatan Fugsional. & 0,1501 \\
\hline & & & $\begin{array}{l}\text { 22c. Rekognisi Dosen(diundang sebagai } \\
\text { pembicara/workshop/konsultan) }\end{array}$ & 0,1869 \\
\hline \multirow{5}{*}{4} & \multirow{5}{*}{ KURIKULUM } & \multirow{5}{*}{0,0983} & $\begin{array}{l}\text { 5. Prosentase mata kuliah yang ada silabus } \\
\text {,SAP dan RPSnya. }\end{array}$ & 0,0667 \\
\hline & & & $\begin{array}{l}\text { 8. Jumlah satker yang diikutkan dalam } \\
\text { perancangan dan pengembangan kurikulum. }\end{array}$ & 0,112 \\
\hline & & & $\begin{array}{l}\text { 15. Prosentase perkuliahan yang sesuai } \\
\text { dengan silabus ,SAP, dan RPSnya. }\end{array}$ & 0,085 \\
\hline & & & $\begin{array}{l}\text { 15a. Kesesuaian Kurikulum dengan capaian } \\
\text { pembelajaran dan kompetensi yang ingin } \\
\text { dicapai. }\end{array}$ & 0,4806 \\
\hline & & & $\begin{array}{l}\text { 15b. Kesesuaian RPS dan SAP dengan } \\
\mathrm{CP}(\text { outcome yang diinginkan). }\end{array}$ & 0,2556 \\
\hline \multirow{6}{*}{5} & \multirow{6}{*}{ FASILITAS } & \multirow{6}{*}{0,0855} & $\begin{array}{l}\text { 11. Rasio kapasitas perpustakaan terhadap } \\
\text { jumlah taruna. }\end{array}$ & 0,0673 \\
\hline & & & $\begin{array}{l}\text { 14. Rasio taruna yang menggunakan fasilitas } \\
\text { Perpustakaan }\end{array}$ & 0,0673 \\
\hline & & & $\begin{array}{l}\text { 14a. Kelengkapan dan sertifikasi } \\
\text { laboratorium guna mendukung penelitian. }\end{array}$ & 0,3432 \\
\hline & & & $\begin{array}{l}\text { 14b. Kelengkapan fasilitas olahraga dan } \\
\text { Kelengkapan fasilitas kesehatan. }\end{array}$ & 0,1411 \\
\hline & & & $\begin{array}{l}\text { 14c. Kelengkapan fasilitas hiburan atau } \\
\text { rekreasi. }\end{array}$ & 0,1411 \\
\hline & & & $\begin{array}{l}\text { 14d. Kelengkapan kelas seperti AC dan } \\
\text { projector. }\end{array}$ & 0,24 \\
\hline 6 & ALINS ALONGINS & 0,0594 & $\begin{array}{l}\text { 24. Rasio alat bantu belajar mengajar dengan } \\
\text { ruang kuliah. }\end{array}$ & 1 \\
\hline \multirow{3}{*}{7} & \multirow{3}{*}{ ANGGARAN } & \multirow{3}{*}{0,058} & $\begin{array}{l}\text { 6. Prosentase laporan keuangan yang tepat } \\
\text { waktu. }\end{array}$ & 0,1058 \\
\hline & & & $\begin{array}{l}\text { 18. Prosentase penelitian dosen yang } \\
\text { mendapatkan dana jurusan. }\end{array}$ & 0,6329 \\
\hline & & & $\begin{array}{l}\text { 21. Prosentase pembayaran gaji dan honor- } \\
\text { honor yang tepat waktu. }\end{array}$ & 0,2613 \\
\hline \multirow{3}{*}{8} & \multirow{3}{*}{ METODE } & \multirow{3}{*}{0,0388} & $\begin{array}{l}\text { 20. Prosentase taruna yang terlibat dalam } \\
\text { penelitian dosen. }\end{array}$ & 0,1057 \\
\hline & & & $\begin{array}{l}\text { 20a. Penerapan metode pengajaran sudah } \\
\text { sesuai dengan SAP dan RPSnya. }\end{array}$ & 0,2602 \\
\hline & & & $\begin{array}{l}\text { 20b. Standar penilaian taruna baik dari } \\
\text { pengetahuan,ketrampilan umum, ketrampilan } \\
\text { khusus,sikap. }\end{array}$ & 0,6341 \\
\hline \multirow{4}{*}{9} & \multirow{4}{*}{ EVALUASI } & \multirow{4}{*}{0,0316} & 9. Prosentase kehadiran peserta pertemuan. & 0,0569 \\
\hline & & & 10. Prosentase program yang terlaksana. & 0,1485 \\
\hline & & & $\begin{array}{l}\text { 10a. Prosentase tercapainya sasaran renops } \\
\text { per tahun. }\end{array}$ & 0,1792 \\
\hline & & & $\begin{array}{l}\text { 10b. Tercapainya outcome yang diinginkan } \\
\text { berdasarkan tracer study. }\end{array}$ & 0,6153 \\
\hline \multirow{3}{*}{10} & \multirow{3}{*}{ PAKET INTRUKSI } & \multirow{3}{*}{0,0303} & 30. Rasio buku petunjuk Praktikum. & 0,1058 \\
\hline & & & $\begin{array}{l}\text { 30a. Bahan ajar yang digunakan harus buku } \\
\text { yang mempunyai rujukan cukup tinggi. }\end{array}$ & 0,6329 \\
\hline & & & $\begin{array}{l}\text { 30b. Peserta didik dapat mengakses } \\
\text { referensi-referensi dan publiser yang } \\
\text { bereutasi. }\end{array}$ & 0,2613 \\
\hline
\end{tabular}


8. Scoring System. Sistem pengukuran kinerja ini adalah merupakan akumulasi pengukuran kinerja dari semua KPI setelah dikalikan dengan bobotnya masing-masing. Misalnya untuk mendapatkan nilai kinerja Anggaran, diperoleh dengan menjumlahkan nilai KPI 6 yang telah dikalikan dengan 0,3266 (bobot KPI 6), KPI 18 dikalikan 0,3562 dan KPI 21 dikalikan 0,3082. Nilai kinerja ini nantinya dikalikan dengan indek bobotnya $(0,1034)$ dan dijumlahkan dengan kinerja kriteria lainnya sebagai nilai kinerja Departemen. Dengan Pendekatan IPMS dapat digambarkan bagaimana pentingnya ukuran kinerja yang kompleks dan kebutuhan untuk menggapai kinerja yang seimbang di sepanjang ukuran kinerja (KPI) tersebut. Sistem pengukuran yang akan diperoleh dibuat dan diolah dengan Microsoft Excel seperti terlihat pada gambar 3

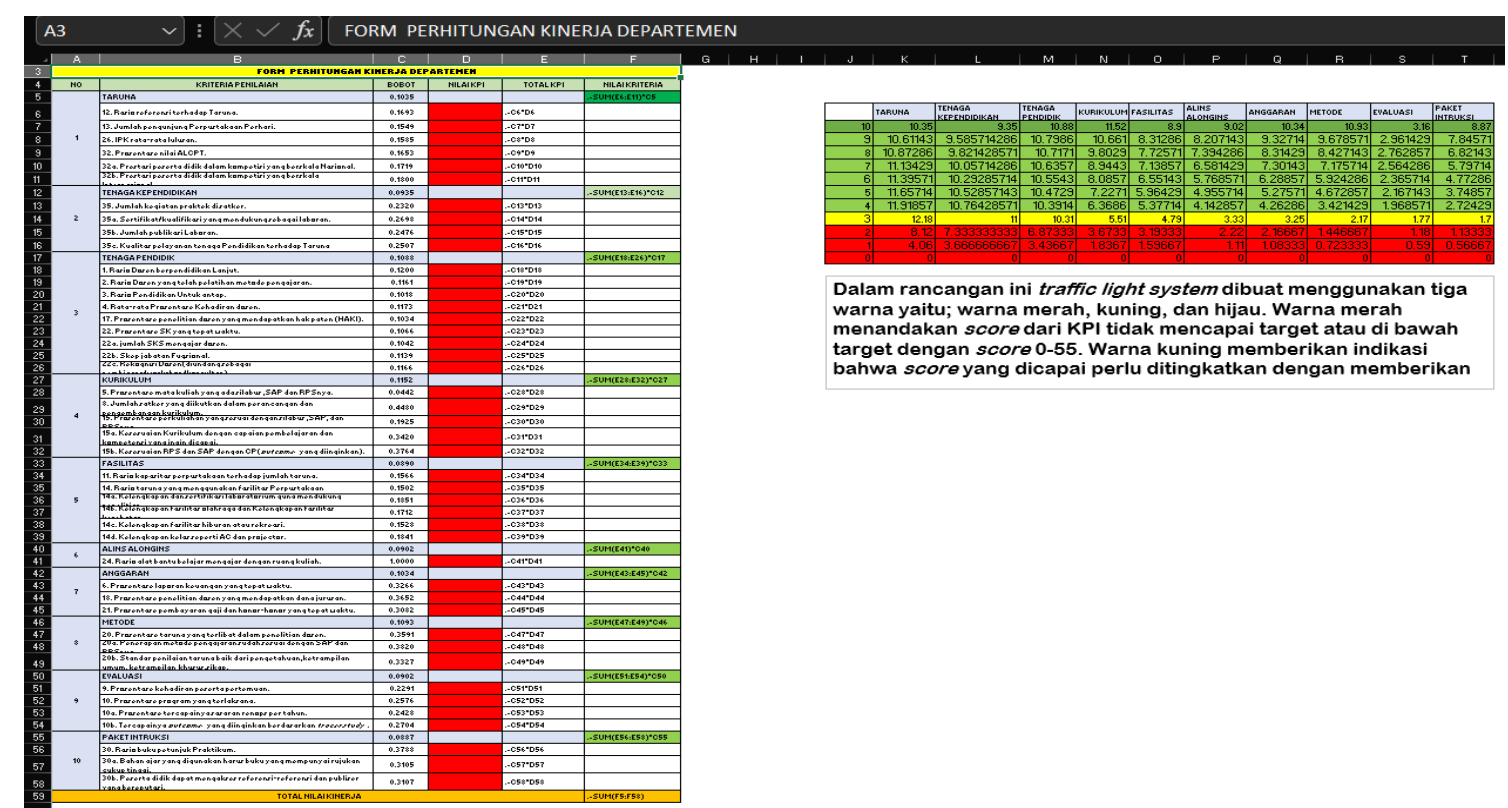

Gambar 3. Tampilan Aplikasi Pengukuran Kinerja Program Studi

\section{IMPLEMENTASI MODEL DAN PEMBAHASAN}

Stakeholder dalam perancangan sistem pengukuran kinerja ini merupakan pihak yang terkait dan berkepentingan terhadap pendidikan di AAU. TNI AU ditempatkan pada level tertinggi pada level organisasi ini disebabkan karena pelaksanaan pendidikan di AAU diarahkan untuk menghasilkan perwira TNI AU, sesuai dengan tugas dari AAU. Sedangkan posisi AAU berada pada level sub-bisnis, dengan perannya sebagai Balakpus pendidikan yang bertanggungjawab terhadap pelaksanaannya. Kemudian berturut-turut Departemen/prodi menjadi stakeholder pada level unit bisnis dengan pelaksanaan pengajaran sebagai proses bisnis yang dijalankan. 13 Stakeholder requirement awal berdasarkan pengukuran kinerja menurut BAN-PT dan penelitian Suartika tentang perancangan sistem pengukuran kinerja di jurusan Teknik Mesin Universitas Mataram [7] yang berjumlah 15 requirement. Dua requirement yang dihapus dan tidak sesuai dengan Pendidikan di AAU adalah kelancaran kenaikan pangkat untuk staf dan dosen serta kemudahan mendapatkan tempat praktek. Kenaikan pangkat untuk staf dan dosen telah diatur tersendiri dengan aturan TNI AU dan secara umum tidak pernah menjadi kendala. Sedangkan kemudahan untuk mendapatkan tempat praktek juga tidak relevan, mengingat selama ini pelaksanaan praktek dilakukan secara terkoordinir dan didukung oleh seluruh satker TNI AU.

Salah satu hal penting yang perlu diketahui dalam perancangan sistem pengukuran kinerja ini adalah mengetahui posisi AAU terhadap kompetitor. Kompetitor AAU sebagai lembaga 
pendidikan militer adalah AKMIL, AKPOL dan, AAL. Akan tetapi ini tidak dapat dilakukan karena selain keterbatasan waktu dan kondisi dalam pengumpulan data, terdapat perbedaan dalam sistem pendidikan di lembaga pendidikan militer lainnya yang dilakukan sesuai kecabangan, dan bukan ilmu akademis umum. Oleh karena itu dalam penelitian ini eksternal monitoring dilakukan dengan cara studi pustaka pada dokumen-dokumen yang yang berkaitan dengan Pendidikan AAU, dengan tujuan untuk memperjelas penentuan objectives, dan juga KPI sekaligus standar pengukuran yang diharapkan dari masing-masing KPI.

Pada perancangan sistem mendapatkan 10 kriteria pengukuran kinerja yang dikembangkan berdasarkan 10 komponen Pendidikan TNI AU dan penelitian Suartika [7]. Hal ini dilakukan karena pembinaan10 komponen Pendidikan ini memegang peranan penting terhadap keberhasilan pelaksanaan proses Pendidikan dalam mencapai tujuan Pendidikan. Kriteria ini kemudian diperinci berdasarkan indikator-indikator/KPI yang sesuai dengan kebutuhan Pendidikan di AAU. Penentuan KPI ini dengan cara wawancara dengan expert yaitu Dirjian dan Ka PM AAU. Pemilihan kedua pejabat ini dikarenakan keterkaitannya dengan tugas jabatan dalam hal pengkajian, pengembangan dan penjaminan mutu Pendidikan yang diselenggarakan di AAU.

Spesifikasi KPI dibuat untuk menjelaskan tentang KPI, meliputi deskripsi, tujuan, target, formula/cara mengukur KPI, frekuensi pengukuran, frekuensi review, pihak yang mengukur, sumber data dan pemilik KPI. Dalam perancangan sistem ini belum lengkap karena sulitnya mendapatkan data yang terkait dengan cara pengukuran target yang ingin dicapai. dikarenakan kedua hal ini ditentukan melalui mekanisme kelompok kerja (pokja).

Hasil Pembobotan. Pembobotan kriteria dan KPI dalam perancangan sistem dilakukan ekspert, yaitu Dirjian, Ka PM, Koordinator Dosen (Koordos), Kadep Aeronautika (AE), Kadep Elektronika (LEK) dan Kadep Teknik Manajemen Industri (TMI). Dirjian dan Ka PM merupakan penyelenggara dari penjaminan mutu di AAU. Koordos merupakan pejabat yang membawahi seluruh dosen yang menjadi salah satu aspek/komponen yang akan diukur kinerjanya. Sedangkan Kadep merupakan pejabat penyelenggaraan pendidikan yang mengetahui segala situasi dan kebutuhan yang harus diperlukan untuk keberhasilan dari penyelenggaraan pendidikan. Sebelum dilakukan pembobotan, susunan kriteria dan KPI dalam diagram hierarki diajukan validasi kepada ekspert.

Scoring System. Pencapaian kinerja Prodi sangat tergantung pada hasil (score) yang didapat pada masing-masing KPI. Pada penelitian ini telah dibuatkan scoring system untuk menilai score yang dapat dicapai.

\section{KESIMPULAN}

Hasil pembobotan didapatkan bahwa kriteria kurikulum merupakan bobot terbesar dengan nilai $11,52 \%$ dan bobot terendah pada Paket intruksi yaitu 8,87\%. Sedangkan bobot terbesar KPI adalah KPI NO 15B, yaitu kesesuaian RPS dan SAP dengan capaian pembelajaran dengan nilai 0,3764. Data ini memperlihatkan bahwa untuk meningkatkan kinerja Departemen AAU, kriteria ini menjadi faktor penentu utama, sehingga perlu mendapatkan perhatian lebih, mulai dari perancangan dampai dengan implementasinya.

Tujuan akhir penelitian tentang implementasi Sistem Pengukuran Kinerja Dengan Metode Integrated Performance Measurement Systems (Ipms) Dan Analytical Hierarchy Process (Ahp) Di Departemen/prodi Akademi Angkatan Udara, adalah mendapatkan suatu alat ukur sistem penilaian kinerja berupa scoring system. Scoring system dalam penelitian ini belum sempurna 
karena belum dapat menentukan nilai kinerja dasar/baseline (ditentukan dengan mekanisme kelompok kerja) dan nilai target yang harus dicapai oleh KPI (pada penelitian-penelitian lain dilakukan dengan metode objective matrix/OMAX). Oleh karena itu agar penelitian ini sempurna perlunya ditambahkan satu metode lagi yaitu metode objective matrix/OMAX.

\section{UCAPAN TERIMA KASIH}

Pada kesempatan kali ini, ucapan terima kasih disampaikan kepada kinerja seluruh tim sehingga naskah penelitian ini dapat diterbitkan. Pada dasarnya penelitian ini masih jauh dari kata sempurna sehingga ke depan masih membutuhkan penyempurnaan pada penelitian berikutnya. Tim peneliti akan menerima segala macam kritik yang membangun bagi terwujudnya naskah penelitian yang lebih baik di masa mendatang. Sebagai bagian dari kolaborasi/kerjasama penelitian antar dosen di AAU, diharapkan akan mampu berbagi pengetahuan untuk meningkatkan kualitas dan kesepahaman teori penelitian AAU di masa mendatang. Selain itu, penelitian ini juga bertujuan untuk meningkatkan ketrampilan dan kredit point bagi dosen sehingga akan meningkatkan akreditasi Lembaga. Oleh karena itu, kerjasama seperti ini diharapkan dapat dilaksanakan dalam berbagai penelitian berikutnya. Kolaborasi yang selaras, terarah dan efektif serta efisien akan mampu memberikan arah yang jelas bagi perkembangan prodi di masa mendatang

\section{REFERENSI}

[1] Cohive, "WWW. Cohive.space," [Online]. Available: https://cohive.space/blogs/society-5-0-untukera-baru-proses-branding/. [Accessed 18 Oktober 2021].

[2] B. University, "BINUS UNIVERSITY, SCHOOL OF COMPUTER SCIENCE," [Online]. Available: https://socs.binus.ac.id/2020/11/01/siapkah-indonesia-menyosong-society-5-0-denganseiring-perkembangan-big-data-yang-semakin-pesat/. [Accessed 13 OKTOBER 2021].

[3] Direktorat Sekolah Dasar, "Menyiapkan Pendidik Profesional Di Era Society 5.0," 3 februari 2021, 2021.

[4] Mabesau, "Peraturan Kepala Staf (PERKASAU) NO 13 Tahun 2019," Organisasi dan Tugas Akademi Angakatan Udara, 2019.

[5] Akademi Angkatan Udara, Program Taruna Gemilang, 1 ed., Yogyakarta, 2021.

[6] BADAN AKREDITASI NASIONAL PERGURUAN TINGGI , "Peraturan Badan Akreditasi Nasional Perguruan Tinggi Nomor 3 tahun 2019 tentang Akreditasi Perguruan Tinggi," 2019.

[7] I. M. Suartika, "Perancangan dan implementasi sistem pengukuran kinerja dengan metode integrated performance measurement systems (studi kasus: jurusan teknik mesin Universitas Mataram)," 2007.

[8] U. Bititci, A. Carrie and L. McDevitt, "Integrated Performance Measurement Systems: A Development Guide.," International Journal of Operations and Production Management, vol. 17, no. 5, pp. 522-534, 1997.

[9] P. Suwignjo, "Sistem Pengukuran Kinerja: Sejarah Perkembangan dan Agenda Penelitian ke," in Proceeding Seminar Nasional Performance Management, Hotel Wisata, Jakarta, 2000.

[10] Mabesau, "Buku petunjuk teknis TNI AU tentang pendidikan ilmu pengetahuan dan teknologi," 2013.

[11] T. L. Saaty, "Some mathematical concepts of the analytic hierarchy process. Behaviormetrika," 1991. 